EGU2020-8109

https://doi.org/10.5194/egusphere-egu2020-8109

EGU General Assembly 2020

(c) Author(s) 2022. This work is distributed under

the Creative Commons Attribution 4.0 License.

\title{
2.5 years of TROPOMI S5P total ozone column data: geophysical global ground-based validation and inter-comparison with other satellite missions
}

Katerina Garane ${ }^{1}$, Maria-Elissavet Koukouli ${ }^{1}$, Tijl Verhoelst ${ }^{2}$, Christophe Lerot ${ }^{2}$, Klaus-Peter Heue $^{3}$, Dimitrios Balis ${ }^{1}$, Alberto Redondas ${ }^{4}$, Andrea Pazmino ${ }^{5}$, Ariane Bazureau ${ }^{5}$, Fabian Romahn ${ }^{3}$, Walter Zimmer ${ }^{3}$, Jian $\mathrm{Xu}^{3}$, Jean-Christopher Lambert ${ }^{2}$, Diego Loyola ${ }^{3}$, Michel Van Roozendael ${ }^{2}$, Florence Goutail ${ }^{5}$, and Jean-Pierre Pommereau ${ }^{5}$

'Laboratory of Atmospheric Physics, Aristotle University of Thessaloniki, Thessaloniki, Greece (agarane@auth.gr)

${ }^{2}$ Royal Belgian Institute for Space Aeronomy (BIRA-IASB), Uccle, Belgium

${ }^{3}$ German Aerospace Centre, Remote Sensing Institute (DLR-IMF), Oberpfaffenhofen, Germany

${ }^{4}$ Izaña Atmospheric Research Center (IARC), State Meteorological Agency (AEMET), Tenerife, Canary Islands, Spain

${ }^{5}$ LATMOS, CNRS, University Versailles St Quentin, Guyancourt, France

The Sentinel-5 Precursor (S5P) mission, launched in October 2017, carries the TROPOspheric Monitoring Instrument (TROPOMI), which provides a daily global coverage at a spatial resolution as high as $5.5 \mathrm{~km} \times 3.5 \mathrm{~km}$ and will extend the European atmospheric composition record initiated with GOME/ERS-2 in 1995. Due to the ongoing need to understand and monitor the recovery of the ozone layer, as well as the evolution of tropospheric pollution, ozone remains one of the leading species of interest during this mission.

In this work, two and a half years of TROPOMI near real time (NRTI) and offline (OFFL) total ozone column (TOC) products are presented and compared to daily and individual, globally distributed, ground-based quality assured Brewer and Dobson TOC measurements. The daily ground-based ozone measurements used here are deposited in the World Ozone and Ultraviolet Radiation Data Centre (WOUDC). The individual Brewer measurements are made available by the European Brewer Network (Eubrewnet). Furthermore, twilight zenith-sky measurements obtained with ZSLDOAS (Zenith Scattered Light Differential Optical Absorption Spectroscopy) instruments, which form part of the SAOZ network (Système d'Analyse par Observation Zénitale), are used for the validation.

The quality of the TROPOMI TOC data is evaluated in terms of the influence of various geophysical quantities such as location, solar zenith angle, viewing angle, season, effective temperature, surface albedo and clouds. The overall statistical analysis of the global comparison shows that the mean bias and the mean standard deviation of the percentage difference between TROPOMI and ground-based TOC is within $0-1.5 \%$ and $2.5 \%-4.5 \%$, respectively. Moreover, based on the full available dataset, a first attempt is made for a drift investigation. 
Additionally, the TROPOMI OFFL and NRTI products are evaluated against already known spaceborne sensors, namely, the Ozone Mapping Profiler Suite, on board the Suomi National Polarorbiting Partnership (OMPS/Suomi-NPP), NASA, and the Global Ozone Monitoring Experiment 2 (GOME-2), on board the Metop-A (GOME-2/Metop-A) and Metop-B (GOME-2/Metop-B) satellites. This analysis shows a very good agreement for both TROPOMI products with well-established instruments, with the absolute differences in mean bias and mean standard deviation being below $+0.7 \%$ and $1 \%$, respectively. 